\section{RMD Open}

Rheumatic \&

Musculoskeletal Diseases

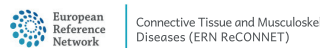

To cite: Cannizzo S, Lorenzoni V, Palla I, et al. Rare diseases under different levels of economic analysis: current activities, challenges and perspectives. RMD Open 2018;4:e000794. doi:10.1136/ rmdopen-2018-000794

Received 6 August 2018 Revised 8 October 2018 Accepted 8 October 2018

\section{Check for updates}

(c) Author(s) (or their employer(s)) 2018. Re-use permitted under CC BY-NC. No commercial re-use. See rights and permissions. Published by BMJ.

Institute of Management, Scuola Superiore Sant'Anna, Pisa, Italy

Correspondence to Professor Giuseppe Turchetti; giuseppe.turchetti@ santannapisa.it

\title{
Rare diseases under different levels of economic analysis: current activities, challenges and perspectives
}

Sara Cannizzo, Valentina Lorenzoni, Ilaria Palla, Salvatore Pirri, Leopoldo Trieste, Isotta Triulzi, Giuseppe Turchetti

\section{ABSTRACT}

Rare diseases imply clinical and economic burden as well as a significant challenge for health systems. One relevant objective of the activities planned within the European Reference Network on Rare and Complex Connective Tissue and Musculoskeletal Diseases (ERN ReCONNET) is to address the economic dimensions of rare diseases to identify, develop and suggest strategies to improve research and patients' access to orphan drugs (ODs) and highly specialised health technologies. This paper presents a preliminary review of the existing policies on rare diseases in the countries of the Network members. It also introduces and discusses the theme of how to perform health economic evaluations of rare diseases and of existing or new treatments for rare diseases. To obtain a preliminary overview aiming at defining the state of the art of rare diseases policies and initiatives in ERN ReCONNET countries, we collected and analysed the rare diseases national plans of all the eight countries of the ERN ReCONNET participants. The preliminary overview that has been performed showed that in all the ERN ReCONNET countries are in place national plans for rare diseases; however, heterogeneity exists in the reimbursement of ODs, direct provision by the healthcare system, involvement of patients' associations in decision making and implementation of clinical practice guidelines.

\section{ECONOMIC AND ORGANISATIONAL CHALLENGES OF RARE DISEASES}

In Europe about 30 million people ( 1 in 17) suffer from a debilitating rare disease (in Europe, a disease is considered rare if it affects 1 person per 2000). Rare diseases imply great clinical and economic burden but also a significant challenge for health systems because of the risk of not responding to patients' needs and of not guaranteeing equal access to treatment. ${ }^{1}$

To address the challenge of rare diseases, the European Commission has selected as strategic objective the improvement of patient access to diagnosis, information and care, and defined specific measures to increase resource use across the European Union (EU). These

\section{Key messages}

What is already known about this subject?

- Rare diseases (RDs) imply great clinical and economic burden but also a significant challenge for the overall healthcare system related to the risk of not responding to patients' needs and not guaranteeing equal access to treatments.

- Despite the efforts made by European and national health organisations to address the economic evaluation issues about RDs, a widely accepted approach for guidelines and practices is still needed.

What does this study add?

- This paper presents a preliminary review of the existing policies on RDs in the countries of the European Reference Network on Rare and Complex Connective Tissue and Musculoskeletal Diseases (ERN ReCONNET) members.

- The study also introduces and discusses the theme of how to perform health economic evaluations in RDs.

How might this impact on clinical practice?

- Supporting the diffusion of novel approaches to perform valuable economic evaluations of RD issues could contribute to the fast and rapid diffusion of best clinical practices and treatments in Europe.

include, in particular, improving recognition and visibility of rare diseases, standardising the coding of rare diseases in all health information systems, supporting national plans for rare diseases, and promoting and funding the creation of European Reference Networks (ERNs).

Among the challenges EU is asking to cope with, we focus on the economic perspective for rare diseases.

In particular, the following are the most relevant dimensions related to the health economic evaluation of existing and new solutions for treating rare diseases:

1. The research-related clinical issues regarding the understanding of the disease and 
the diagnosis (ie, lack of familiarity with the rare disease, disease heterogeneity, lack of established diagnostic criteria, misdiagnosis, geographical variation), the development of effective treatments (ie, heterogeneity of treatment effects) and the recruitment of patients (ie, geographical limitations, disease coding systems, ethical and privacy issues).

2. The demonstration of the value for money, the achievement of reimbursement and patients' access to care (lack of sufficient clinical data, lack of validated instruments to assess relevant endpoints).

3 . The equity of access and other social concerns (economic pressure on healthcare budgets, unmet needs, equal access to high-quality healthcare services and to technology across geographical regions). ${ }^{2}$

4. The techniques and tools to be used for performing the health economic evaluation of alternative care/ therapeutic approaches for rare diseases.

In this scenario, only a multilevel, multidimensional strategy can be effective for managing such a complex problem.

\section{THE EUROPEAN RESPONSE}

The European response to economic and organisational challenges

Since the end of the 20th century, the issues and implications of rare diseases and orphan drugs (OD) policy were under the concerns of the European institutions. ${ }^{3}$ More precisely, starting in 1999 with the (EC) 141/2000 on Orphan Medicinal Products, ${ }^{4}$ the European Community began a series of legislative and policy commitments around strategies to improve public health and care plan for rare diseases.

This regulation act established for the first time in Europe the standard definition of rare disease, setting in not more than 5 per 10000 persons affected the maximum value of the prevalence that defines a disease as a rare one. As well, the EU regulation n. 141/2000 underlined the need at the national level to offer more incentives in favouring the recognition and treatment of rare diseases, and in incentivising drug development, whose research and development costs may not be covered only by market sales.

In 2008 the European Commission realised a report, ${ }^{5}$ underlying the necessity to put more efforts in tackling rare diseases as a public health policy issue that requires a set of application strategies and guidelines coherent at the European level to support specific actions in the Member States. As a result, in 2009 the European Council of health ministries adopted an action plan for rare diseases in which a set of detailed recommendations triggered the development and adoption of national plans for rare diseases by the end of $2013 .^{6}$

Meanwhile, many projects were financed by the EU under the framework programme of the community action in the area of public healthcare. ${ }^{7}$

Moreover, rare diseases action programme was heavily addressed in 2011 with the Directive EU n. 24 on the application of patients' rights in cross-border healthcare. ${ }^{8}$ The goal of the directive was to improve the access and the possibility to share practices and interest about rare diseases care across the European Member States. The directive identified the main circumstance in which patients can seek care in other EU countries than the residential one, and Article 12 provided the development of the ERNs.

The European Directive on the application of patients' rights in cross-border healthcare established in 2011 a legal framework for cross-border healthcare in Europe and favoured cooperation between the health systems also with the promotion of ERNs. ${ }^{9-11}$

The establishment of ERNs has the aim to create excellent organisational and clinical models around 'families' of rare diseases, grouped on the basis of clinical areas, to allow inclusiveness and overcome fragmentation characterising single rare diseases. The idea is to support and favour the linking of European centres of expertise and professionals in different countries to share knowledge and identify alternative treatment options, and to facilitate research and spread innovation, with the ultimate goal of allowing all EU patients to have access to the best care. ${ }^{12}$ Support and cofunding to ERNs were provided by the European Commission. ${ }^{11}$ After the evaluation of 5-year priorities and objectives, a total of 24 ERNs were launched in March 2017, and among these ERN ReCONNET is the ERN on Rare and Complex Connective Tissue and Musculoskeletal Diseases (rCTDs). The ERN ReCONNET multiannual work plan (5-year plan), taking the challenge of the 'economic dimension' of rCTDs, also includes organisational and economic dimensions as among the priorities to be addressed involving experts in the context of rheumatic disease and their economic impact, ${ }^{13-22}$ and networking with different professionals and patient representatives.

The idea is that in the frame of the collaborative intelligence created within and across the ERNs, to face and discuss the issue of organisational and economic dimensions will be necessary to achieve the overall goal of delivering and providing access to the best possible care.

This objective will be pursued taking into account also matured experience in the field in recent years. Nowadays in EU countries even though there are still difficulties and disparities in the development and reimbursement of ODs (ie, drugs that are able to treat diseases so rare that, under usual market conditions, pharmaceutical companies are reluctant to develop them) and in the provision of innovative and highly specialised health technologies (HSHTs) for the diagnosis and treatment of rare diseases, in the last years some initiatives have been developed to deal with economic and organisational challenges of rare diseases. ${ }^{12}$ European research projects such as Social Economic Burden and Health-Related Quality of Life in Patients with Rare Diseases in Europe (BURQoL) ${ }^{23}$ European Network for Health Technology Assessment (HTA) ${ }^{24}$ and Advanced HTA, ${ }^{25}$ and special interest groups such as the National Institute for Health and Care Excellence ${ }^{26}$ and International Society for 
Pharmacoeconomics and Outcomes Research (ISPOR) Rare Disease Group, ${ }^{27}$ devoted their attention to the challenges of health economics (HE) for rare diseases and OD reimbursement. Available evidence about the implications for HTA in the context of rare diseases as well as examples of frameworks developed in specific contexts where dedicated pathways for HSHTs and ODs have been established are described in a document from the Kidney Disease Improving Global Outcomes and the London School of Economics. ${ }^{28-36}$

The core message of these initiatives and scientific reports highlights and in some cases defines models for a more comprehensive assessment of the economic and socioeconomic impact of rare diseases, also stressing the importance of valuing the patient's voice.

These efforts did not evolve until now in the practical development of a paradigm shift across EU, nor in the resolution of disparities among countries. Differences in the implementation of rules (eg, health technology assessment) for allocating healthcare resources in general, and in particular in the eventual definition and adoption of specific processes for rare diseases, characterise the current scenario. ${ }^{37-40}$ Moreover, despite the existence and some degree of homogeneity among recommendations across countries, many practices still differ. ${ }^{37}$

In addition, since 2015 when the EU set the orphan drug designation which established rules to offer incentives for companies to research and develop medicines for rare diseases that otherwise would not be developed, ${ }^{41}$ an impact in terms of increasing development and reimbursement of ODs in the EU has still not been demonstrated. ${ }^{42}$

\section{Rare diseases policies and initiatives in the ERN ReCONNET countries}

At the national level, in Europe, there is heterogeneity regarding the national policies, national plans and strategies for rare diseases. It is the case of countries involved in the ERN ReCONNET initiative.

The preliminary overview that has been performed showed that in all the ERN ReCONNET countries are in place national plans for rare diseases. ${ }^{43-48}$ In six countries either some funding initiatives have been designed for the reimbursement of ODs (Belgium, France, Germany, Italy, Portugal) or direct provision by the healthcare system is in place (The Netherlands). The involvement of patient associations in decision making has been integrated in six countries (Belgium, France, Germany, Italy, Portugal, The Netherlands); clinical practice guidelines for rare diseases have been implemented in five countries (France, Germany, Italy, Portugal, The Netherlands); and in four countries funds for the implementation of the plans have been dedicated (France, Germany, Romania, The Netherlands). Finally, in Italy there is a patient pathway dedicated to rare diseases. In addition, table 1 summarizes the main results obtained in the preliminary overview regarding the rare disease activities in ERN ReCONNET countries. A more detailed description of the results is available in the online supplementary table $\mathrm{S} 1 .^{49-59}$
Rare diseases national plans are tools for the implementation of public health strategy in the field of rare diseases at the national level. Since 2009 the value of these national plans has been underlined at the European level by the Council Recommendation on European Action in the Field of Rare Diseases (2009/C 151/02), for the adoption of national plans that follow the guidelines and recommendations elaborated by the EUROPLAN project (cofunded by the EU Commission for the promotion and implementation of national plans or strategies in rare diseases). Within the framework of national health and social systems, the national plans should (1) guide the relevant actions to guarantee access to high-quality care and to effective ODs for patients with rare diseases; (2) integrate measures at the local, regional and national levels for a harmonised approach; and (3) define priority actions with operating objectives and follow-up activities. Rare diseases national plans represent the strategies for the constitution of implementation of national (and regional) rare diseases networks. The national networks cooperate with the ERNs in a collaborative manner to establish a common exchange of knowledge and mobility of expertise.

\section{The current approach in health economic evaluation}

The process of evaluating healthcare programmes is usually based on the interrelated hypotheses of (1) resource scarcity; (2) technology (drugs or medical devices) as a given good; (3) constant returns of scale for health resource allocation in order to avoid switching phenomena in which an increasing investment could transform a previously dominated solution into a dominant alternative; (4) individual preferences in condition of risk represented by expected utility, and so: rationality of agents and their expectations and heuristics, as refinements adopted to reduce multiple equilibria agents can compute; (5) short-run horizon; (6) finite in number and fixed over time states of nature; (7) equilibrium; and (8) isomorphism, up to symmetric and non-systemic errors, between properties individually observed and inferred from samples to the general population.

Under these hypotheses there is an optimum criterion for allocating resources: ordering alternatives according to their efficiency, that is, on the basis of cost and effectiveness ratios. In the set of endpoints that are usually adopted for measuring the effectiveness of alternative solutions-and despite the increasing objections-utility and expected utility as measures representing patients' preferences in a 'certain' or in a 'risky' world, respectively, are now a standard. ${ }^{60-62}$

Small samples and high heterogeneity among patients and in the evolution of the disease for each patient are the most relevant challenges in assessing the effectiveness and costs of treatments for rare diseases.

Therefore, we believe that traditional approaches could not be appropriate for assessing the cost and effectiveness of rapidly changing conditions and high heterogeneity, as experienced in rare diseases. New solutions and 
Table 1 A summary overview of rare disease activities in ERN ReCONNET countries

\begin{tabular}{|c|c|c|c|c|c|}
\hline $\begin{array}{l}\text { Country/ } \\
\text { Activities }\end{array}$ & $\begin{array}{l}\text { Centers of expertise } \\
\text { for rare diseases }\end{array}$ & $\begin{array}{l}\text { Sharing information, } \\
\text { patient support }\end{array}$ & $\begin{array}{l}\text { Clinical Practice } \\
\text { guidelines and best } \\
\text { practice; Registries }\end{array}$ & $\begin{array}{l}\text { Access to healthcare } \\
\text { services and orphan } \\
\text { drugs }\end{array}$ & $\begin{array}{l}\text { Organization } \\
\text { of care }\end{array}$ \\
\hline Belgium & $\begin{array}{l}\text { Annualnational funded } \\
\text { NPRD*; three levels } \\
\text { of networks for rare } \\
\text { diseases. }\end{array}$ & $\begin{array}{l}\text { Maininformation } \\
\text { provided by RaDiOrg* } \\
\text { patients' organization. }\end{array}$ & $\begin{array}{l}\text { CPGs }^{*} \text { not produced at } \\
\text { national levels. The Central } \\
\text { Registry for RDs* is in } \\
\text { place. Specific diseases } \\
\text { registries also available. }\end{array}$ & $\begin{array}{l}\text { About n. } 78 \text { ODs* available } \\
\text { (end of 2016). }\end{array}$ & $\begin{array}{l}\text { Neonatal screening } \\
\text { programs regulated } \\
\text { by regional law. }\end{array}$ \\
\hline France & $\begin{array}{l}\text { NPRDsince 2004. } \\
\text { Third plan 2018-2022 } \\
\text { approved on July } 2018 \text {. }\end{array}$ & $\begin{array}{l}\text { Main information } \\
\text { developed and } \\
\text { provided by Orphanet. }\end{array}$ & $\begin{array}{l}\text { National standard of care } \\
\text { for RDs are provided by } \\
\text { reference centres. }\end{array}$ & $\begin{array}{l}\text { Essential services } \\
\text { and products may be } \\
\text { reimbursed, included off- } \\
\text { label products. }\end{array}$ & $\begin{array}{l}\text { Neonatal screening } \\
\text { programs available. }\end{array}$ \\
\hline Germany & $\begin{array}{l}\text { RD centres of expertise } \\
\text { implemented by the } \\
\text { federal structure of } \\
\text { the healthcare system } \\
\text { (limited list diseases). }\end{array}$ & $\begin{array}{l}\text { Information developed } \\
\text { by Orphanet, and a } \\
\text { national helpline for } \\
\text { patients was setup. }\end{array}$ & $\begin{array}{l}\text { CPGs available for some } \\
\text { rare diseases. }\end{array}$ & ODs fully reimbursed. & $\begin{array}{l}\text { Neonatal screening } \\
\text { programs available. }\end{array}$ \\
\hline Italy & $\begin{array}{l}\text { NPRD 2013-2016 } \\
\text { approved in October } \\
\text { 2014. National and } \\
\text { regional designation } \\
\text { process for } \\
\text { identification of centres } \\
\text { of expertise for RDs } \\
\text { (hospitals) since 2001. }\end{array}$ & $\begin{array}{l}\text { Information developed } \\
\text { and provided by } \\
\text { Orphanet and a } \\
\text { national helpline for } \\
\text { patients was setup. }\end{array}$ & $\begin{array}{l}\text { CPGs produced and } \\
\text { implemented at national } \\
\text { level. Registries:National } \\
\text { RD Registry and Regional } \\
\text { RD registries projects are } \\
\text { funded by NHS*. }\end{array}$ & $\begin{array}{l}\text { ODs are provided by the } \\
\text { NHS following the same } \\
\text { coverage for all other } \\
\text { medicinal products. }\end{array}$ & $\begin{array}{l}\text { Neonatal screening } \\
\text { programs available. } \\
\text { RD patient pathway } \\
\text { available. }\end{array}$ \\
\hline Portugal & $\begin{array}{l}\text { RDs centres of } \\
\text { expertise are } \\
\text { recognized by an official } \\
\text { act of the Minister of } \\
\text { Health under a National } \\
\text { strategy for RDs. }\end{array}$ & $\begin{array}{l}\text { Information developed } \\
\text { by Orphanet, and a } \\
\text { national helpline for } \\
\text { patients was setup. }\end{array}$ & $\begin{array}{l}\text { CPGs produced and } \\
\text { implemented at national } \\
\text { level. Nonational or } \\
\text { regional registries. }\end{array}$ & $\begin{array}{l}\text { Patient access services } \\
\text { provided by RD card } \\
\text { since } 2013 \text {. NHS covers } \\
\text { all patients on a national } \\
\text { reimbursement list basis. }\end{array}$ & $\begin{array}{l}\text { Neonatal screening } \\
\text { programs available. }\end{array}$ \\
\hline Romania & $\begin{array}{l}\text { NPRD adopted at the } \\
\text { end of } 2013 \text { funded } \\
\text { through national } \\
\text { legislation (no dedicated } \\
\text { budget). }\end{array}$ & $\begin{array}{l}\text { Public funded national } \\
\text { RDs information, } \\
\text { helplines are in place. }\end{array}$ & $\begin{array}{l}\text { No CPGs for RDs. (at the } \\
\text { date of 2016).National } \\
\text { or regional RD registries } \\
\text { missing. Disease specific } \\
\text { registries available. }\end{array}$ & $\begin{array}{l}\text { Some genetic tests are } \\
\text { provided to patinets free } \\
\text { of charge. ODs are both } \\
\text { commercialized and free } \\
\text { of charge for patients. }\end{array}$ & Not found \\
\hline Slovenia & $\begin{array}{l}\text { NPRD adopted covering } \\
\text { the period } 2012-2020 \text {. }\end{array}$ & $\begin{array}{l}\text { Information developed } \\
\text { by Orphanet, and a } \\
\text { national helpline for } \\
\text { patients wassetup. }\end{array}$ & $\begin{array}{l}\text { CPGs adopted at national } \\
\text { level for some diseases. }\end{array}$ & $\begin{array}{l}\text { Specific programs and } \\
\text { facilities are in place to } \\
\text { support people with RDs } \\
\text { (individual care plans, } \\
\text { access to social and } \\
\text { support services). }\end{array}$ & $\begin{array}{l}\text { Neonatal screening } \\
\text { programs available. }\end{array}$ \\
\hline $\begin{array}{l}\text { The } \\
\text { Netherlands }\end{array}$ & $\begin{array}{l}\text { NPRD adopted in } \\
2003 \text { with allocated } \\
\text { structured budget. }\end{array}$ & $\begin{array}{l}\text { Information developed } \\
\text { by Orphanet, and a } \\
\text { national helpline for } \\
\text { patients was setup. }\end{array}$ & $\begin{array}{l}\text { NCPGs produced. } \\
\text { A national policy for } \\
\text { development, adoption } \\
\text { and implementation of } \\
\text { CPGs is in place. }\end{array}$ & ODs fully reimbursed. & $\begin{array}{l}\text { Neonatal screening } \\
\text { programs available. }\end{array}$ \\
\hline
\end{tabular}

*NPRD, National Plan for Rare Diseases; RDs, Rare Diseases; RaDiOrg, Rare Disease Organization Belgium; ODs, Orphan Drugs; CPGs, Clinical Practice Guideline and best practice; RDs, Rare Diseases; NHS, National Healthcare System.

methods can transform the current paradigm of analysis as discussed in the following paragraph.

\section{Recommendations for performing economic evaluation in rare diseases}

Alternative approaches: complexity, heterogeneity and evolution Agent-based modelling

Appearing more suitable for assessing the impact of new therapies in a changing environment, alternative evolutionary-based paradigms, if adopted for a dynamic HTA, can be more appropriate for assessing and comparing rare disease therapies.
Alternative approaches like agent-based modelling (ABM) will allow health economists to take into account heterogeneity, adaptation and learning, a mix that is the true endogenous engine of the evolution of social and interacting systems; to reproduce the effects of institutions on individual behaviours and the health and economic global variables; to analyse interactions and emerging patterns in evolving environments; and to inform policy decision makers on the emerging effects of changes. Moreover, by modelling the behaviour of multiple agents (those relevant figures involved in the problem, that is, 
patients, caregivers, clinicians, policymakers and so on), ABMs have the potentiality to capture the spectrum of consequences and effects produced by rare diseases, and rCTDs too, that go also beyond the mere clinical picture or effectiveness and involve the specific interaction with available treatment, and the interplay of patients (and their heterogeneity) with peers and with the overall environment they live in (the health systems too).

While the first applications of ABMs in health disciplines found their natural application in simulating the effects of virus contagion from infectious diseases, like HIV and influenza, due to agents' interactions and some vaccination policies ${ }^{63-66}$ due to their flexibility, ABMs have been currently adopted for modelling the interaction of heterogeneous agents and different stakeholders in the treatment and management of some chronic diseases. ${ }^{67}$ The use of this kind of models is also challenging in evaluating possible drivers of treatment efficacy and effectiveness and their clinical and economic impact, as the impact of medication adherence and/or non-adherence in the evolution of rare diseases. ${ }^{68}$

In brief, new approaches will overcome the limits of the current methods (mainly based on ad hoc, time and spatially constrained experiments), making heterogeneity and complexity experienced in case of rare diseases a source of information rather than an obstacle to be bypassed for a real surveillance over time.

\section{The Big Data perspective}

The importance of the environment patients live, their interaction with peers and in particular social interaction also bring to the potential of the Big Data analysis. The emergence of Big Data analysis is nowadays largely recognised as one of the most important socioeconomic shifting paradigms derived from digital socialisation, ${ }^{69}$ supported by social networks and the technological improvement of cloud technology. ${ }^{70}$

The Big Data revolution is able to sustain the shift from the current to a new era of HTA indicated for a dynamic perspective in assessing the impact of therapies adapted for rare diseases.

Some examples on study design and statistical methods are presented and discussed below.

\section{Study design and data collection towards a dynamic approach}

The exclusive positioning that randomised clinical trials (RCTs) are occupying in the scale of evidence came to be reconsidered. Novel adaptive-based $(\mathrm{AB})^{71-79}$ and pragmatic approaches appear more challenging. In this, although $\mathrm{AB}$ trials are biased (this bias, however, can be controlled), they have the advantage over RCTs on the probability that, on average, patients receive the most effective therapy (adopting a Pólya urn approach, a simple demonstration of this is available in Mahmaud ${ }^{80}$ ).

This method has some relevant limitations, such as that it needs more time than a traditional one, while the most relevant challenge is that it is able to mime the current clinical practice where physicians adapt and learn on the basis of the observed reaction to therapies. The current practice should be considered a continuum and ongoing adaptive clinical trial through which we can observe and learn, updating our knowledge on the disease and its evolution (ie, a natural synthesis between adaptive control trials and the Bayesian approach). ${ }^{81}$

In this, rare diseases could become the first application of a new dynamic approach on HTA in which there is no more distinction between analyses on trial and continuum analysis on the current practice.

To improve the comparison of studies and obtain more information from analysis and meta-analysis, a fundamental direction for HTA in rare diseases is the creation of an EU standard that encourages researchers and scientists to adopt the same criterion for selecting the more appropriate methodologies for the analysis. Big data and international registries could improve our knowledge on the field, and heterogeneity could be a resource only in case of homogeneous or comparable methods of analysis.

\section{Statistics}

A dynamic HTA needs a rethinking of the approaches usually adopted for analysing data. In this scenario, two alternatives are available.

Providing the current traditional framework for the health economic evaluation, the frequentist/classical approach $(\mathrm{FA})^{82} 83$ relies on the assumption that an uncertain phenomenon can be described by an unknown probability distribution whose parameters are fixed and their values could be estimated sampling from that distribution. This approach can experience limits in case of rare diseases.

As opposed to the frequentist approach, the Bayesian perspective $(\mathrm{BP})^{84}$ conceives probability distributions associated with a phenomenon as the model of our knowledge/ignorance for that phenomenon. Our knowledge/ignorance is updated according to the availability of novel evidence and information.

In this, $\mathrm{BP}$ is closer to the concept of 'learning by data' and inductive reasoning, and it also better copes with the possibility of continuously updating knowledge.

To also catch the opportunities offered by the widespread diffusion of Big Data, no definite advice probably exists in the dilemma of adopting FA or BP or hybrid approaches $^{85}$; it depends on the specific situation we are in.

Nevertheless, the apparent balance and comparability of FA and BP could not be the same when we are interested in assessing the impact of HTA in the rapidly changing and complex environment of rare diseases.

\section{CONCLUSIONS}

In a context where organisational and economic issues about rare diseases are still a challenge and there is high heterogeneity in guidance and practice as well as lack of transparency or methods, ${ }^{86}$ ERN ReCONNET can offer a real opportunity to develop novel solutions to 
address current challenges and issues related to rCTDs. At the same time, rCTDs could also be the ideal context for testing potentialities and limits of the novel HTA approaches, as a starting point for applications in other contexts and diseases.

Diffusion of novel approaches, when proven to provide advantage, requires a new mentality among all the professionals and stakeholders involved (eg, decision makers, health economists, clinicians and so on), which could be driven by the development of a 'guide' concerted with relevant stakeholders.

In conclusion, this work represents the first summary of an overall identification of the different economic evaluations for rare diseases in Europe, the state of the art, and a descriptive analysis of how governments and local authorities try to tackle this issue.

Moreover, to the best of our knowledge, currently there is a lack of general guidelines for performing economic evaluations of rare diseases, which implies the necessity to coordinate in developing a wider and more effective comprehension of the best practices and activities able to fill this lack.

As a future task, this work aims at overcoming the limits of this preliminary analysis and updating the knowledge of economic evaluation for rare diseases with more evidence on methods and approaches when these become available in ERN ReCONNET.

Future activities will be focused on defining guidelines for assessing the effectiveness and costs of alternative therapies for rare diseases considering the existing and new paradigms of analysis within the ERN ReCONNET network.

Two related questions are mandatory to cope with rare diseases in the years to come. First, how to fund and incentivise research on and second how to reimburse the research outcomes in rare diseases. The second question indicates a specific issue that needs solutions: which criteria, methods and tools (also far from a traditional measure of efficiency) can be adopted to estimate the economic and social burden of a rare disease, and to compare alternative solutions in a budget constraint scenario. These questions can be resolved only at an international level through new connections and team working of experts coming from different initiatives and international networks for rare diseases.

Acknowledgements Thanks to all the members of the Steering Committee of the ERN ReCONNET for the huge commitment during this work. A special thank goes to all the members of the ERN ReCONNET team for providing support during all the phases of the Work Package 3.

Contributors All authors contributed equally to the paper.

Funding This publication was funded by the European Union's Health Programme (2014-2020)

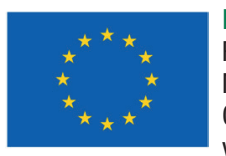

Disclaimer ERN ReCONNET is one of the 24 European Reference Networks (ERNs) approved by the ERN Board of Member States. The ERNs are co-funded by the European Commission. The content of this publication represents the views of the authors only and it is their sole responsibility; it cannot be considered to reflect the views of the European Commission and/or the
Consumers, Health, Agriculture and Food Executive Agency (CHAFEA) or any other body of the European Union. The European Commission and the Agency do not accept any responsibility for use that may be made of the information it contains.

Competing interests None declared.

Patient consent Not required.

Provenance and peer review Commissioned; externally peer reviewed.

Data sharing statement The article does not contain original data.

Open access This is an open access article distributed in accordance with the Creative Commons Attribution Non Commercial (CC BY-NC 4.0) license, which permits others to distribute, remix, adapt, build upon this work non-commercially, and license their derivative works on different terms, provided the original work is properly cited, appropriate credit is given, any changes made indicated, and the use is non-commercial. See: http://creativecommons.org/licenses/by-nc/4.0/.

\section{REFERENCES}

1. EMA, 2017. Available from: http://www.ema.europa.eu/docs/en_GB/ document_library/Leaflet/2017/12/WC500240710.pdf [accessed 26 Jul 2018].

2. ISPOR. Rare Disease Research, HTA and Evidence for Reimbursement, ISPOR 20th Annual European Congress, Glasgow 6th November, 2017.

3. Rodwell C, Aymé S. Rare disease policies to improve care for patients in Europe. Biochim Biophys Acta 2015;1852(10 Pt B):2329-35.

4. Regulation (EC) $\mathrm{N}^{\circ} 141 / 2000$ of the European Parliament and of the Council. December 1999 on orphan medicinal products December 16 1999. Available from: http://eurlex.europa.eu/LexUriServ/ LexUriServ.do?uri=OJ:L:2000:018:0001:0005:en:PDF

5. Europe's challenges COM (2008) 679 final, 2008. Communication from the Commission to the European Parliament, the Council, the European Economic and Social Committee and the Committee of the Regions on Rare diseases. Available from: http://ec.europa.eu/ health/ph_threats/non_com/docs/rare_com_en.pdf

6. Council recommendation on an action in the field of rare diseases (2009/C 151/02) June 2009. 2009. Available from: http://eurlex. europa.eu/LexUriServ/LexUriServ.do?uri=OJ:C:2009:151:0007:0010: EN:PDF

7. Projects financed concerning the rare diseases in the field of healthcare by the Second Community Programme. Available from: http://ec.europa.eu/health/rare_diseases/projects/index_en.htm

8. Directive 2011/24/EU of the European Parliament and of the Council on the application of patients' rights in cross-border healthcare. 2011. Available from: http://eur-lex.europa.eu/LexUriServ/ LexUriServ.do?uri=OJ:L:2011:088:0045:0065:EN:PDF

9. Directive 2011/24/EU of the European Parliament and of the Council of 9 March 2011 on the application of patients' rights in cross-border healthcare. Journal of the European Union 2011;88:45-65.

10. 2014/286/EU: Commission Delegated Decision of 10 March 2014 setting out criteria and conditions that European Reference Networks and healthcare providers wishing to join a European Reference Network must fulfill Text with EEA relevance. Journal of the European Union 2014;147:71-8.

11. 2014/287/EU: Commission Implementing Decision of 10 March 2014 setting out criteria for establishing and evaluating European Reference Networks and their Members and for facilitating the exchange of information and expertise on establishing and evaluating such Networks Text with EEA relevance. Journal of the European Union 2014;147:79-87.

12. Evangelista T, Hedley V, Atalaia A, et al. The context for the thematic grouping of rare diseases to facilitate the establishment of European Reference Networks. Orphanet J Rare Dis 2016;11:17.

13. Turchetti G, Scalone L, Della Casa Alberighi O, et al. The rationale of pharmacoeconomic analysis in rheumatologic indications. Clin Exp Rheumatol 2012;30(4 Suppl 73):S64-S71.

14. Turchetti G, Yazdany J, Palla I, et al. Systemic lupus erythematosus and the economic perspective: a systematic literature review and points to consider. Clin Exp Rheumatol 2012;30(4 Suppl 73):S116-S122.

15. Pierotti F, Palla I, Pippo L, et al. Budget impact analysis of belimumab in treating Systemic Lupus Erythematosus. Int J Technol Assess Health Care 2016;32:348-54.

16. Pierotti F, Palla I, Treur M, et al. Assessment of the Economic Impact of Belimumab for the Treatment of Systemic Lupus Erythematosus in the Italian Setting: A Cost-Effectiveness Analysis. PLoS One 2015;10:e0140843.

17. Specchia ML, de Waure C, Gualano MR. Health technology assessment of belimumab: a new monoclonal antibody for the 
treatment of systemic lupus erythematosus. Biomed Res Int 2014;2014:1-9.

18. Furneri G, Mantovani LG, Belisari A, et al. Systematic literature review on economic implications and pharmacoeconomic issues of rheumatoid arthritis. Clin Exp Rheumatol 2012;30(4 Suppl 73):S72-S84.

19. Trieste L, Palla I, Fusco F, et al. The economic impact of gout: a systematic literature review. Clin Exp Rheumatol 2012;30(4 Suppl 73):S145-S148

20. Palla I, Trieste L, Tani C, et al. A systematic literature review of the economic impact of ankylosing spondylitis. Clin Exp Rheumatol 2012;30(4 Suppl 73):S136-S141.

21. Trieste L, Palla I, Baldini C, et al. Systemic vasculitis: how little we know about their societal and economic burden. Clin Exp Rheumatol 2012;30(4 Suppl 73):S154-S156.

22. Della Rossa A, Neri R, Talarico R, et al. Diagnosis and referral of rheumatoid arthritis by primary care physician: results of a pilot study on the city of Pisa, Italy. Clin Rheumatol 2010;29:71-81.

23. Available from: https://www.eurordis.org/content/burqol-rd-project-0

24. EUnetHTA. 2018. European network for Health Technology Assessment(EUnetHTA). Available from: https://www.eunethta.eu/ [Accessed 26 Jul 2018]

25. Advance HTA. Available from: http://www.advance-hta.eu/ [accessed 26 Jul 2018].

26. National Institute for Health and Care Excellence, 2018. Interim process and methods of the Highly Specialised Technologies Programme. NICE. Available from: https://www.nice.org.uk/Media/ Default/About/what-wedo/NICE-guidance/NICE-highly-specialisedtechnologies-guidance/Highly-Specialised-Technologies-Interimmethods-and-process-statements.pdf [accessed 26 Jul 2018]

27. ISPOR Rare Disease Group. Available from: https://www.ispor.org/ sigs/RareDiseases.asp [accessed 26 Jul 2018].

28. Available from: https://kdigo.org/wp-content/uploads/2017/02/1.Angelis-Aris_Health-Economics.pdf

29. Drummond MF, Wilson DA, Kanavos P, et al. Assessing the economic challenges posed by orphan drugs. Int J Technol Assess Health Care 2007;23:36-42.

30. Graf von der Schulenburg JM, Frank M. Rare is frequent and frequent is costly: rare diseases as a challenge for health care systems. Eur J Health Econ 2015;16:113-8.

31. López-Bastida J, Oliva-Moreno J. Cost of illness and economic evaluation in rare diseases. Adv Exp Med Biol 2010;686:273-82.

32. Nicod E, Berg Brigham K, Durand-Zaleski I, et al. Dealing with uncertainty and accounting for social value judgments in assessments of orphan drugs: evidence from four european countries. Value Health 2017;20:919-26.

33. Nicod E, Annemans L, Bucsics A, et al. HTA programme response to the challenges of dealing with orphan medicinal products: Process evaluation in selected European countries. Health Policy 2017.

34. Annemans L, Aymé S, Le Cam Y, et al. Recommendations from the european working group for value assessment and funding processes in rare diseases (ORPH-VAL). Orphanet J Rare Dis 2017;12:50.

35. Nicod E, Kanavos P. Scientific and social value judgments for orphan drugs in health technology assessment. Int $J$ Technol Assess Health Care 2016;32:218-32.

36. Nicod E. Why do health technology assessment coverage recommendations for the same drugs differ across settings? Applying a mixed methods framework to systematically compare orphan drug decisions in four European countries. Eur $\mathrm{J}$ Health Econ 2017;18:715-30.

37. Nicod E, Kanavos P. Developing an evidence-based methodological framework to systematically compare HTA coverage decisions: A mixed methods study. Health Policy 2016;120:35-45.

38. Drummond $\mathrm{M}$, de Pouvourville $\mathrm{G}$, Jones $\mathrm{E}$, et al. A comparative analysis of two contrasting European approaches for rewarding the value added by drugs for cancer: England versus France. Pharmacoeconomics 2014;32:509-20.

39. Medic G, Korchagina D, Young KE, et al. Do payers value rarity? An analysis of the relationship between disease rarity and orphan drug prices in Europe. J Mark Access Health Policy 2017;5:1299665

40. Zelei T, Molnár MJ, Szegedi M, et al. Systematic review on the evaluation criteria of orphan medicines in Central and Eastern European countries. Orphanet J Rare Dis 2016;11:72.

41. European Medicines Agency 2018. Rare diseases, orphan medicines Getting the facts straightAvailable from: http://www.ema.europa.eu/ docs/en_GB/document_library/Other/2018/02/WC500244578.pdf [accessed 26 Jul 2018].

42. Gammie T, Lu CY, Babar ZU-D. Access to orphan drugs: a comprehensive review of legislations, regulations and policies in 35 countries. PLoS One 2015;10:e0140002.
43. European Project for rare Diseases National Plan Development - EUROPLAN. Available from: http://www.europlanproject.eu [accessed 26 Jul 2018].

44. EUCERD - European Union Committee of Experts on Rare Diseases. Available from: http://www.eucerd.eu/?page_id=3029 [accessed 26 Jul 2018].

45. RD Action - Data and Policies for Rare Diseases. Available from: http://www.rd-action.eu [accessed 26 Jul 2018].

46. National Action League for People with Rare Diseases of German healthcare system. Available from: http://namse.de/english.html [accessed 26 Jul 2018].

47. Ministère de Solidarités et de la Santé. Available from: http:// solidarites-sante.gouv.fr/soins-et-maladies/prises-en-chargespecialisees/maladies-rares/article/les-maladies-rares [accessed 26 Jul 2018].

48. Ministere des affaires sociales et de la Santé Publique Belgique. Available from: https://www.health.belgium.be/sites/default/files/ uploads/fields/fpshealth_theme_file/plan_belge_maladies_rares.pdf [accessed 26 Jul 2018].

49. RD-Action, State of the Art of Rare Disease - Activities in EU Member States and Other European Countries. Belgium Report.

50. Belgium Report. BELGIUM EUROPLAN ROUND TABLE in the framework of the EU Joint Action RD-ACTION 6. Brussels Final Report 2017

51. Rodwell C, Aymé S, eds. "Report on the State of the Art of Rare Disease Activities in Europe", 2014.

52. RD-ACTION. State of the Art for Rare Diseases - Activities in EU Member States and Other European Countries, Italy Report.

53. OECD 2017. European Observatory on Health Systems and Policies (2017). In: . Italy: Country Health Profile State of Health in the EU, OECD Publishing, Paris/European Observatory on Health Systems and Policies, Brussels, 2017.

54. RD-Action. State of the Art of Rare Disease - Activities in EU Member States and Other European Countries. Portugal Report.

55. EUROPLAN NATIONAL CONFERENCE in the framework of the EU Joint Action RD-ACTION Zalău, 16-172017

56. RD-Action. State of the Art of Rare Disease - Activities in EU Member States and Other European Countries. Slovenia Report.

57. RD-Action. State of the Art of Rare Disease - Activities in EU Member States and Other European Countries. Netherlands Report.

58. Dharssi S, Wong-Rieger D, Harold M, et al. Review of 11 national policies for rare diseases in the context of key patient needs. Orphanet J Rare Dis 2017;12:63.

59. Gammie T, Lu CY, Babar ZU. Access to orphan drugs: a comprehensive review of legislations, regulations and policies in 35 countries. PLOS One 2015;10:e0140002.

60. Turchetti G, Spadoni E, Geisler E, et al. Evaluation of biomedical innovative technologies. IEEE Eng Med Biol 2010;29:70-6.

61. Drummond MF, Sculpher MJ, Torrance GW, et al. Methods for the Economic Evaluation of Health Care Programmes. Oxford: Oxford University Press, 2005

62. Briggs A, Claxton K, Sculpher M. Decision Modelling for Health Economic Evaluation. Oxford University Press: Oxford, 2006.

63. Kumar S, Grefenstette JJ, Galloway D, et al. Policies to reduce influenza in the workplace: impact assessments using an agentbased model. Am J Public Health 2013;103:1406-11.

64. Parker J, Epstein JM. A distributed platform for global-scale agentbased models of disease transmission. ACM Trans Model Comput Simul 2011;22:1-25.

65. Lee BY, Brown ST, Korch GW, et al. A computer simulation of vaccine prioritization, allocation, and rationing during the $2009 \mathrm{H} 1 \mathrm{~N} 1$ influenza pandemic. Vaccine 2010;28:4875-9.

66. Marshall BDL, Friedman SR, Monteiro JFG, et al. Prevention and treatment produced large decreases in HIV incidence in a model of people who inject drugs. Health Aff 2014;33:401-9.

67. Lee $\mathrm{W}, \mathrm{Noh} \mathrm{Y}$, Kang $\mathrm{H}$, et al. The mediatory role of medication adherence in improving patients' medication experience through patient-physician communication among older hypertensive patients. Patient Prefer Adherence 2017;11:1119-26.

68. Trieste L, Pirri S, Turchetti G. An Agent-based model of medication adherence to competing drugs with physician mediation and network reinforcement. mimeo,2018.

69. Hart AD. The digital invasion: how technology is shaping you and your relationships. Grand Rapids, Michigan: Baker Books, 2013.

70. Marston S, Li Z, Bandyopadhyay S. Cloud computing - the business perspective. Decision Support Systems 2001;51.

71. Chin R. Adaptive and Flexible Clinical Trials. Broken Sound Parkway (NW CRC Press), 2012.

72. Chow SC, Chang M. Adaptive design methods in clinical trials - a review. Orphanet J Rare Dis 2008;3:11. 
73. Dirienzo AG. Using urn models for the design of clinical trials. The Indian J of Statistics 2000;62:43-69.

74. Wei LJ, Smythe RT, Lin DY, et al. Statistical Inference with Data-Dependent Treatment Allocation Rules. J Am Stat Assoc 1990;85:156-62.

75. Rosenberger WF, Lachin JM. The use of response-adaptive designs in clinical trials. Control Clin Trials 1993;14:471-84.

76. Zuidgeest MGP, Goetz I, Groenwold RHH, et al. Series: Pragmatic trials and real world evidence: Paper 1. Introduction. J Clin Epidemiol 2017;88:7-13.

77. Oude Rengerink K, Kalkman S, Collier S, et al. Series: Pragmatic trials and real world evidence: Paper 3. Patient selection challenges and consequences. J Clin Epidemiol 2017;89:173-80.

78. Welsing PM, Oude Rengerink K, Collier S, et al. Series: Pragmatic trials and real world evidence: Paper 6. Outcome measures in the real world. J Clin Epidemiol 2017;90:99-107.
79. Irving E, van den Bor R, Welsing P, et al. Series: Pragmatic trials and real world evidence: Paper 7. Safety, quality and monitoring. J Clin Epidemiol 2017;91:6-12.

80. Mahmaud HM. Pólya Urn Models. Chapman and HallCRC, 2009.

81. Williamson SF, Jacko P, Villar SS, et al. A Bayesian adaptive design for clinical trials in rare diseases. Comput Stat Data Anal 2017;113:136-53.

82. Willan AR, Briggs AH. Statistical Analysis of Cost-effectiveness Data. New York: Wiley, 2006.

83. Gray AM, Clarke PM, Wolstenholme JL. Applied methods of costeffectiveness analysis in health care. Oxford University Press, 2010

84. de Finetti B. Sul significato soggettivo della probabilità. Fund Math 1931:17-298.

85. Efron B. Modern science and the Bayesian-frequentist controversy. Stanford University, 2005.

86. Mincarone P, Leo CG, Sabina S, et al. Reimbursed Price of Orphan Drugs: Current Strategies and Potential Improvements. Public Health Genomics 2017;20:1-8. 